\title{
COMMUNITY RESPONSE GRIDS: USING INFORMATION Technology to Help Communities Respond to BIOTERROR EMERGENCIES
}

Paul T. Jaeger, Kenneth R. Fleischmann, Jennifer Preece, Ben Shneiderman, Philip Fei Wu, and Yan Qu

Access to accurate and trusted information is vital in preparing for, responding to, and recovering from an emergency. To facilitate response in large-scale emergency situations, Community Response Grids (CRGs) integrate Internet and mobile technologies to enable residents to report information, professional emergency responders to disseminate instructions, and residents to assist one another. CRGs use technology to help residents and professional emergency responders to work together in community response to emergencies, including bioterrorism events. In a time of increased danger from bioterrorist threats, the application of advanced information and communication technologies to community response is vital in confronting such threats. This article describes CRGs, their underlying concepts, development efforts, their relevance to biosecurity and bioterrorism, and future research issues in the use of technology to facilitate community response.

I N THE EVENT OF A BIOTERRORIST ATTACK or other biosecurity emergency, communication and information sharing are central to community response. Questions that will need to be considered include:

- How can technology be used to collect as much information as possible about the event as it is occurring to understand the full extent of the emergency and identify the greatest risks to the community?

- How will responding organizations coordinate their actions in real-time as the event unfolds? How can limited resources best be positioned to meet the needs created by the emergency?

- How will life-saving information get to responders from biosecurity/bioterorrism experts who may not be in the area as the emergency occurs?
- How will the government effectively provide accurate, trusted information to community residents about the actions that they need to take? How can this same information best be used to limit rumors and panic?

- How will residents be able to communicate their needs in the emergency to responders and to other residents, particularly members of their social networks? How can technology help to gather information about what social networks or specific populations may have been most affected by the emergency?

- How can residents be informed of ways to provide resident-to-resident assistance and find out who needs such assistance?

In a time of an increased potential for bioterrorist and biosecurity emergencies, the development of improved informa-

Paul T. Jaeger, PhD, JD, is an Assistant Professor, College of Information Studies, and Director, Center for Information Policy and EGovernment; Kenneth R. Fleischmann, PhD, is an Assistant Professor, College of Information Studies, and an Assistant Director, Center for Information Policy and E-Government; Jennifer Preece, PhD, is Professor and Dean, College of Information Studies; Ben Shneiderman, PhD, is a Professor of Computer Science; Fei Philip Wu is a doctoral student in the College of Information Studies; and Yan $\mathrm{Qu}, \mathrm{PhD}$, is an Assistant Professor, College of Information Studies; all are at the University of Maryland, College Park. 
tion and communication technologies is vital for effective community response to such emergencies when they occur.

This article explores the roles of information and communication in community response to bioterrorist and biosecurity emergencies, specifically using Community Response Grids (CRGs). We detail the design, concepts, and goals of CRGs, with particular emphasis on their relevance to biosecurity and bioterrorist emergencies. By integrating Internet and mobile technologies, CRGs will enable residents to report information, professional emergency responders to disseminate accurate and reliable instructions, and residents to provide assistance to one another. CRGs are intended to use technology to enable residents and professional emergency responders to communicate and share information in community response to emergencies.

While CRGs are a new concept and are currently being prototyped, developed, and tested, we believe that the conceptual and technological issues embodied in CRGs are compelling enough to merit scholarly and professional discussion before they are fully tested. Currently, the research team is implementing a CRG for the University of Maryland campus (see http://www.cs.umd.edu/hcil/911gov for details of the development efforts). Although the prototyping of the University of Maryland CRG and other efforts will undoubtedly reveal many operational issues that have to be addressed, the CRG concept and approach offer many points to consider as a means of overcoming the limitations of current warning technologies, of harnessing social networks, and of amplifying societal resilience to extreme events. Discussion of these concepts and approaches while initial CRGs are being prototyped and implemented can serve not only to advance conceptual and technical issues being considered in the context of emergency response, but also to provide feedback to help improve CRGs from the outset of their implementation.

\section{Why COMMUnity Response GRIDS?}

During a large-scale emergency, access to information is vital to community response and recovery for both residents and professional emergency responders. Such access allows community members to coordinate their actions to cope with events as they occur and to deal with the aftermath of the event. Key types of vital information during an emergency include information necessary to:

- Alert first responders

- Coordinate emergency response

- Notify community members

- Gather facts about the situation

- Connect family and friends

- Identify those in need of assistance

- Share updates about conditions
In any emergency situation, both professional emergency responders and residents need immediate access to information. Emergency responders have knowledge and equipment to deal with medical, fire, and law enforcement needs before and during the emergency. Residents may help to identify an emergency, may help others avoid it, and can play a significant role in recovery.

Recent events have demonstrated the need to rethink the ways in which information is accessed, exchanged, and distributed in large-scale emergencies, particularly in the use of technology. With currently available technologies, professional emergency responders frequently face breakdowns in communication. ${ }^{1}$ Implementation of new information technologies in emergency response has the potential to significantly improve communication and coordination. ${ }^{2,3} \mathrm{~A}$ more robust information network with greater distribution could further improve communication and coordination in emergencies. ${ }^{4}$

Based on lessons from recent medical crises (SARS), natural catastrophes (Hurricanes Katrina and Rita, the Asian tsunami), incidents of large-scale violence (the shootings at Virginia Tech), and terrorism (9/11, the London and Madrid bombings), telephone, radio, and television-based emergency response systems cannot meet all of the needs of communities. Further, as the Virginia Tech incident demonstrated, the use of online alert methods-such as email alone-is of little value if people are not likely to be near computers when the email is sent. Sadly, the limited impact of an email alert in that case demonstrates the problem of relying wholly on one-way alert systems, which many colleges and communities have adopted in the wake of the incident at Virginia Tech. Replacing older systems of limited impact with newer systems of limited impact is not really progress.

The combination of mobile telecommunications devices and the Internet with traditional alert methods like landlines and radio, however, has the potential to provide higher capacity and more effective service, as well as to create interactive communication mechanisms that can simultaneously reach many more citizens and government officials. ${ }^{5}$ Internet-based systems are particularly appealing for emergency response and recovery, because the Internet was originally developed as a national security measure that would continue working in the event of the destruction of major communication points, intelligently routing traffic around congested or nonfunctioning parts of the system. ${ }^{4,6}$ Instead of expecting residents to maintain and have access to battery-powered radios as part of an emergency kit, it is more timely and appropriate to base emergency information and response on increasingly ubiquitous portable, wireless devices such as cell phones, PDAs, and laptop computers. Further, creating an emergency information system that allows residents to both send and receive information from the sys-

Biosecurity and Bioterrorism: Biodefense Strategy, Practice, and Science 
tem through the same communication technologies increases its value to residents and professional emergency responders.

Although there has been much discussion about emergency response, particularly in relation to the "war against terror" and in the wake of Hurricane Katrina, surprisingly little attention has been given to developing strong social networks empowered with appropriate technology to promote resident-to-resident assistance and foster coordinated emergency response throughout a community, a region, or even a nation. After a major disaster, community involvement through social networks is extremely important. After the Kobe earthquake, for example, $80 \%$ of victims were saved by friends and neighbors who sought to help members of their social networks. ${ }^{7,8}$ Information and communication technologies supported networks of rural quarantined farmers in the UK during the foot-and-mouth disease outbreak. ${ }^{9}$ After the Asian tsunami, online communities proved more effective than structured relief agencies at targeting volunteers to the places where their unique skills would be most effective. ${ }^{10}$

A web-based emergency system would facilitate these social networks in helping communities respond to emergencies in two ways. As in the Kobe earthquakes, CRGs will help members of existing social networks to provide assistance to one another. Also, as during the Asian tsunami, the CRG will provide a means for residents to develop new spontaneous social networks to provide and coordinate resident-to-resident assistance.

The goal of CRGs is to bridge the opportunities created by new technologies with the power of social networks to develop systems that will provide robust and resilient means for community response to emergencies. Communication and coordination are among the most pressing issues in an emergency. ${ }^{11}$ Disasters are "occasions in which the boundaries between organizational and collective behavior are blurred." ${ }^{\circ}$ Community Response Grids are designed to facilitate information access and exchange between and among residents and professional emergency responders.

Drawing on lessons from previous emergencies in terms of technology function, communication channels, and information needs of residents and emergency responders, the key design elements of CRGs are:

- Use multiple platforms and communication channels (landlines, cell phones, handhelds, desktops, laptops);

- Use various forms of content to support redundancy and universal usability (text, photos, video);

- Trusted by users;

- Use multiple communication channels;

- Based on social networks; and

- Use highly localized information.
Because social networks are vital to community responses, the Internet provides a unique means to connect the social networks in a community when a response is needed, especially since individuals are becoming very comfortable with social uses of the Internet. Further, the concepts underlying CRGs are inherently scalable from the size of a small community (i.e., a university campus) to a city or even a state.

The catastrophic results of failing to properly exchange information between residents and professional emergency responders during an emergency were evidenced in the failures in the response to Hurricane Katrina. Secretary of Homeland Security Michael Chertoff told Congress, "During the Katrina response, our efforts were significantly hampered by a lack of information on the ground." ${ }^{2}$ The White House report on the failures of the Katrina response observed, "Inability to connect multiple communication plans and architectures clearly impeded coordination and communication at the federal, state, and local levels." 13 Later investigations, however, have strongly suggested that government officials had access to large amounts of information about the extent of the situation and in many cases failed in interagency coordination and communication of information. ${ }^{14-17}$ Because of this combined lack of information, communication, and coordination, the federal, state, and local government agencies and private organizations did not know what functions they were expected to provide in the response, they did not have any guidance on how their functions were to coordinate and interrelate, they lacked an overall operational concept, and they had no system to track and share information. ${ }^{18}$ Technologies like the Internet and mobile communication devices provide avenues to bring lessons from responses to previous emergencies into preparing for future community response to emergencies.

\section{The Roles of CRGs in an EMERGENCY}

Community Response Grids support leveraging the power of both residents and professional emergency responders by recognizing and coordinating their contributions. This section examines the potential for CRGs specifically in relation to user populations, access and trust, community involvement, and other contexts.

\section{Users}

Among residents, CRGs leverage existing social networks and encourage new ones by allowing residents to register at any time. Users are able to build personal profiles, communicate with other members of their social networks, and list assistance they would need in certain types of emergencies. Kapucu notes, "Communities that have strong working relationships on a daily basis generally function better in 
emergency situations because of increased trust." ${ }^{6}$ Community Response Grids build on these existing social networks and the trust they engender, while allowing registered users to build new social networks through the system.

During an emergency, threat denial will be the immediate response of most residents, followed by trying to confirm the threat; yet, actual response times will vary greatly among individuals. ${ }^{19}$ By having a system that allows realtime communication between residents and professional emergency responders, CRGs will work to improve resident response times and awareness levels. Users also will be able to send real-time messages to request help from responders and other residents. In their personal profiles, users will be able to indicate what types of help they anticipate they might be able to provide (e.g., the ability to take three other people in their car if an evacuation is ordered) and what types of help they might need (e.g., not having a car and needing a ride if an evacuation is ordered). These social networks that are built into the CRG will enable local populations to self-organize and respond by helping each other in situations where centralized services are overwhelmed by an emergency. Similarly, the capacities of CRGs will be useful in informing residents that there is not an emergency when reports of an emergency are incorrectly circulating.

As can be seen in Figure 1, CRGs allow residents to communicate what is occurring and what is needed in real-time to professional emergency responders by computer, cell phone, and other mobile communication devices. Figure 1 shows how web-based interactions with the CRG appear on the system being developed for the University of Maryland. Users will be able to report, receive, and share information with both professional emergency responders and other local residents, simultaneously facilitating communication among professional emergency responders, from residents to emergency responders, from emergency responders to residents, and among residents.

Users register a profile in the CRG, noting where they live, where they work, what social networks in the community they belong to, and other information that will help to localize the information they receive from the system. They also will be able to participate in online social networks through the CRG. To make use of the CRG a commonplace, if not everyday, information activity, the University of Maryland CRG is being incorporated into the university's new web portal, which all students, faculty, and staff will be using for their official online information activities. Users also can designate all the ways they wish the system to reach them: email accounts, cell phone numbers, landline numbers, handheld devices, or others.

\section{Community Involvement}

Direct citizen involvement is extremely important in emergency response and recovery, with the potential to notice- ably speed both response to and recovery from an emergency. ${ }^{20}$ Pre-existing community engagement and social networks are important in allowing "leaders to face the complex and ever-shifting realities of an extreme event." 21 Increases in the number of active citizens, and therefore citizen responders, will allow decision makers to better allocate government resources where they are needed most. ${ }^{21}$

Community Response Grids build on the fact that the natural reaction of most residents in a community is to help one another in an emergency. Tierney and colleagues observed, "Rather than being dazed and in shock, residents of disaster-stricken areas are proactive and willing to assist one another." 22 It has long been recognized that, immediately following an emergency, community members will generally be very altruistic in helping others through search and rescue and caring for the injured as a result of social norms favoring assistance, the urgent need to act, the typical delay in external help arriving, and the isolating effects of a disaster. ${ }^{23,24}$ Communities with strong social ties and networks before an emergency will be better prepared to respond to emergencies, and collective action in emergencies is most effective when it is based on pre-existing social networks. ${ }^{22}$

People may respond differently to different kinds of emergencies, based partly on their familiarity with the type of emergency; however, previous experience with a particular type of emergency does not have an impact on the coalescing of social networks to meet rescue and care needs for community members. ${ }^{22}$ Relatives, neighbors, friends, and others affected in the same emergency frequently serve as the basis of social networks for rescue and care, even when previous disaster experience is minimal among members of the population. ${ }^{22,25}$

Successful community engagement in preparation for emergencies requires involvement of residents, community partners, agency heads, and people who have historically been marginalized or underserved, as well as adequate resources, administrative commitment, and sufficient time to develop a viable plan. ${ }^{21}$ Community Response Grids also will support coordination among professional emergency responders, allowing them to gather many reports rapidly, to promptly recognize patterns, and to coordinate response activities. Simultaneous input from professional emergency responders and residents will provide a more accurate portrait of the severity and breadth of an emergency. During an emergency, the rate of decision making at lower levels of organizations, and therefore the need for information, increases sharply. ${ }^{31}$ Community Response Grids provide the needed information to all levels of professional emergency responders to ensure the necessary information is accessible to those who need it to make decisions.

\section{Information Access and Trust}

Community Response Grids are in no way meant to limit the means of access to emergency information to any popu- 
JAEGER ET AL.

UNIVRSITY OF

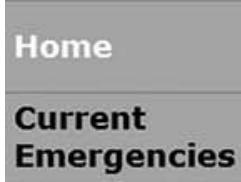

Report Emergency

Offer Help

Past Events

Training \&

Preparation

Discussion Forum

My Profile

\section{College Park, Maryland}

\section{Community Response Grid}

\section{Home}

The community response grid (CRG) at the University of Maryland provides up-to-date emergency information. You can also report emergencies, request help, and assist others in your community.

\section{Breaking News!}

- University closed today due to the upcoming snow storm. All classes after 12:00 pm cancelled.

- Two gun shots were heard north to the stadium. Police are securing the area.

\section{Current Situation (last update: 11:29am Jan 15, 2007)}

Click the dots on the map to get details

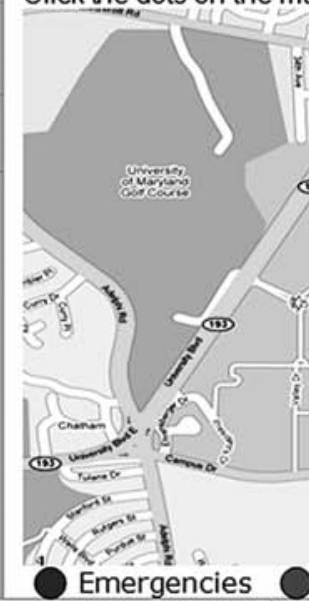

Welcome, John Smith!

You are a registered member of:

- College of Information Studies (CLIS)

- CLIS-doc

- $\underline{\text { CLIS movie club }}$
Important contacts:

UM Police

(911 or 301-405-3333)

UMD Health Center

(301-314-8180)

Report Suspicious Activity

to DHS

(1-866-347-2423)

Federal Emergency

Management Agency

(1-800-621-FEMA)

Citizen Corps

Ready.gov

Figure 1. University of Maryland Community Response Grid

lation. Many different types of media can be used to share information in an emergency, but they will only be effective to the extent that people have access to the technologies being used to share information. ${ }^{26}$ Further, a wide range of factors, including language barriers, cultural differences, socioeconomic status, and levels of trust in government, can make certain groups harder to reach with emergency information. ${ }^{17,27,28}$ By working in tandem with traditional methods for reporting and receiving emergency information-landlines, the Emergency Alert System, radio, television-CRGs expand the number of ways in which emergency information can reach residents. The greater number of technologies involved also will help provide a consistent message to residents. Currently, different information channels (radio, television, alert sirens, etc.) give differing messages with unequal amounts of specificity in an emergency, and residents vary in which media they will respond to. 22

From the standpoint of citizens, an important developmental aspect of CRGs will be the cultivation of trust in the
CRG and the emergency information it provides. Successful risk communication is based on contextualizing and personalizing the risk to engender trust. ${ }^{22}$ In high stress situations, people base the majority of their credibility assessments on how trustworthy a source is - not its level of expertise. ${ }^{29}$ Individuals who trust a source find its risk estimates more credible and its policies more acceptable. ${ }^{30}$

Professional staff monitoring the CRG will separate out suspicious or low-priority reports and assign appropriate resources to the major problems. Community Response Grids employ visual analytic tools that assist the monitoring by showing temporal patterns of requests, offers of assistance, and levels of discussion, as well as which individuals are more likely to request and offer assistance. These features will be essential in helping professional emergency responders handle the volumes of information and identify any incorrect reports. Citizens and responders are equally prepared to recognize threats, but they can be inclined to interpret some of them differently. ${ }^{27}$ The expanded forms of content (i.e., video, pictures) that citizens will be able to 
submit to emergency responders will greatly improve the ability of citizens to convey threats to responders. The video and pictures also will greatly improve the ability of emergency responders to analyze what is being reported and assess the true nature of any potential threat.

\section{Professional Emergency Responders and Information Exchange}

Exchange of information among professional emergency responders is a major problem in emergency response. While this has been clearly understood and documented in the Katrina response, this problem also affected the 9/11 response. During 9/11, the New York City police and fire departments were unable to communicate because of incompatible radio systems. The fire department was still using the same analog radios that had failed in the same ways during the response to the 1993 attack on the World Trade Center. ${ }^{32}$ A total of 1,607 government and nongovernment organizations were involved in the response to 9/11 terror attacks in New York City, ${ }^{6}$ so the information-sharing issues between the fire and police were but a small part of the overall information exchange issues in the response.

In the United States, there are approximately 30,000 local governments, 30,000 local fire departments, 18,000 local police departments, 15,000 school districts, and 3,400 county governments. ${ }^{33}$ Further, many emergency management personnel, like FEMA and state emergency managers, "are embedded in a network of thousands of nonprofit organizations, private firms, ad hoc groups, individual firms, and public safety agencies that are all responding to the disaster," according to Wise. ${ }^{18}$ As a result, as Waugh and Sylves note, the "disaster network is loosely structured, organizationally diverse, motivated by a broad range of interests, and in part ad hoc." 34 Access to a system designed specifically to promote information sharing would be a huge improvement in coordination among the many organizations that are typically involved in emergency response.

In a major natural disaster, such as a large-scale earthquake, a CRG could play many significant roles in community response, including the following:

- Residents could request help from responders and other residents;

- Residents could identify to whom in their social networks and in their local area they could provide assistance;

- Professional emergency responders could coordinate between agencies to allocate resources to the maximum extent possible;

- Professional emergency responders could use submitted text, photo, and video reports of the damage in specific locations to determine which types of aid were most needed and in which locations;
- Emergency responders could send messages to residents of local areas who were particularly vulnerable to after-effects, such as areas where gas mains were broken or areas most likely to have powerful aftershocks;

- Emergency responders could send messages to residents of areas that need to be evacuated;

- Emergency responders could send messages to residents (on a block-by-block basis) regarding where to seek shelter, emergency supplies, and other types of support; and

- Residents could be coordinated to provide long-term support and help during recovery within the community.

Because the CRG is designed to employ a range of mobile and Internet technologies, it will greatly increase the chances that vital messages can still be sent and received from the most heavily damaged areas. Like many other vital government functions, the CRG must be located in a building that has emergency backup power to continue functioning and receive inputs from whatever types of technology are still operable. If an earthquake knocked out power and landlines, for example, cell phones and PDAs could still be available to connect to the CRG.

\section{RELATED EFFORTS FOR COMMUNITY ENGAGEMENT IN EMERGENCIES}

There is a significant need for a system that incorporates multiple channels, information flows, types of technologies, and social networks for responding to emergencies. There is considerable focus on the need for community response networks, disruption-tolerant networks, and technology that can be used to facilitate participation in emergency situations. ${ }^{35-37}$ However, the combination of new technologies and social networks has not been sufficiently pursued in the development of new types of emergency alert systems.

The radio-based Emergency Alert System, originally created in 1951, has been relied on in the U.S. to broadcast information in a crisis. Despite its reliability and range, radio provides only one-way communication. As traditional local media have disappeared (e.g., local newspapers) or been purchased by multinational corporations (e.g., local radio stations), the need for new means to foster community response to emergencies has grown. ${ }^{38,39}$ For example, when a train derailment sent a cloud of poisonous gas floating toward Minot, Minnesota, local officials were unable to use the radio to alert the townspeople because all six local radio stations were owned by one national media corporation and the stations played only feeds of preprogrammed music from a distant source. Local officials were unable to get any response from the corporation's national offices to announce the impending danger; as a result, one resident died from exposure to the gas and more than a thousand were injured. ${ }^{38}$

Biosecurity and Bioterrorism: Biodefense Strategy, Practice, and Science 
Telephone-based systems also have significant limitations. For example, during and after the 9/11 attacks in New York City, cell phones and land lines were limited by a combination of the loss of cell towers, broken lines, and volume of usage being attempted. ${ }^{40}$ With limited telephone capacities, rescue personnel in New York City had serious problems sharing information, coordinating efforts, gathering data, identifying false information, and directing efforts. ${ }^{41}$ The difficulties with information led to similar problems in the aftermath of Hurricane Katrina, as delay, duplication, lack of coordination, and confusion proved deadly. ${ }^{42}$

The provision of information alone through websites has proved insufficient to deal with local emergencies. ${ }^{43}$ In crisis situations, insufficient or incorrect information can lead to either complete inaction or disastrous action. ${ }^{42,44}$ As noted above, the email alert system employed by Virginia Tech proved ineffective because the emails were sent when few people were near computers.

There have been several attempts to set up community networks for business and social interaction-most notably in Blacksburg, Virginia; Seattle; and the San Francisco Bay area, as well as in the Netherlands, Italy, the UK, Tokyo, and Shanghai-but not specifically for emergency response purposes. ${ }^{45-47}$ Their success is mixed, and they have not had to react to an event of the magnitude of the terrorist attacks of $9 / 11$, the Asian tsunami, or Hurricane Katrina. Many communities_such as Dane County, Wisconsin (http://www.countyofdane.com/ems/popwarn.htm), and Fairfax, Virginia (https://www.fairfaxva.gov/emas/)—have also expanded the ways in which citizens can be notified of emergency information, including email alerts tailored to where they live. Such government online emergency systems, and the systems sold as software packages, lack the community-building components and often do not allow for multichannel communication. The Dane County system, for example, provides many ways to get information to citizens, but it has no community response functions, professional emergency responder or resident coordination, or ways for residents to report information beyond traditional 911 calls.

Community Response Grids, by incorporating both mobile telecommunications and the Internet into the mix of technologies traditionally used for emergency information to allow multidirectional communication and by leveraging social networks for coordination, will significantly address these types of problems in times of a major disaster.

\section{CRGS AND OTHER INFORMATION CHANNELS IN EMERGENCIES}

Community Response Grids also are intended to acknowledge that residents and professional emergency responders do not exist in a social vacuum during an emergency. There are certain trusted social institutions that people will turn to for information in an emergency, and there are also certain institutions that government agencies will want to use to try to coordinate emergency response.

Following the major hurricanes of 2004 and 2005 that wreaked havoc throughout much of the southeastern U.S., many residents and responders turned to public libraries for information related to response and recovery. The social trust that most people place in public libraries and the resonance between the values of libraries and of the communities that they serve were key reasons why they became unexpected emergency information centers. ${ }^{48,49}$ The main types of emergency information that residents and responders sought from public libraries were: highly localized news and satellite maps about areas affected, government and insurance forms, means of communicating with relief organizations and government agencies, access to government information, and information about missing and displaced persons and pets. ${ }^{50-52}$

Three major lessons can be drawn from the reliance on public libraries for emergency information in the context of CRGs. First, residents prefer to receive emergency information from sources they trust. This lesson is extremely important in making the development of social networks a central part of CRGs. Second, residents seek emergency information that is as localized as possible to the areas they are interested in, driving the CRGs to focus on developing ways to provide highly localized information to users. Third, responders need reliable information systems by which to communicate with other responders in the emergency area and with others outside of the emergency area. Thus, a central aspect of CRGs will be to ensure that responders and coordinating agencies have means of communicating in some format to coordinate their activities and receive vital information from outside the emergency area.

"E-government" - that is, the provision of government information and services online-also has a role to play in the development of CRGs. It has already been suggested that e-government has the potential to play several key roles in emergency response: pre-disaster planning, post-disaster evaluation, coordination, service and benefit delivery, and providing information to the public. ${ }^{53}$ However, this list fails to account for the ability of e-government to allow members of the public to report information to responders and to allow responding agencies to communicate and share information with one another. Thus far, e-government sites primarily have been used to encourage individuals to prepare for an emergency rather than to coordinate community response or interagency coordination.

Just as government agencies will have clear reasons to employ the e-government infrastructure during emergencies, CRGs employed at the local or state level can be synched to appropriate e-government websites to provide government information and services to residents and re- 
sponders. For example, a CRG could be used to send the links to online government forms, such as FEMA forms, that residents will have to complete, while responders could be sent links to federal government response guidelines and coordination plans for specific types of emergencies as they occur.

\section{Potential Roles of CRGS IN RESPONDING TO BIOTERRORISM}

Although CRGs hold a great deal of promise for assisting residents and responders in coping with and recovering from a range of emergencies, CRGs present several specific opportunities for emergencies related to biosecurity and bioterrorism.

1. Disseminating accurate information. If a bioterrorist attack is threatened or has occurred, a CRG would provide health officials with a channel for disseminating trusted information to residents about the appropriate actions to take in response to the threat. This information could be disseminated in as localized a manner as necessary to give different instructions to different locations within the affected area.

2. Rumor/panic control. If a bioterrorist attack is threatened or has occurred, a CRG would provide health officials a means for squelching rumors about the situation. By providing accurate updates about what is actually happening, the CRG could be used to limit the amount of inaccurate information that residents in the affected area are acting on. When the correct information is available to most residents, the possibility of public panic also will be reduced.

3. Track biosecurity and bioterror events as they unfold. With real-time reporting from residents and responders to the CRG of what is happening in an affected area, health officials will be able to track every aspect of a biosecurity/bioterror event as it unfolds. With such information, health officials and other professional emergency responders will be better able to determine the extent of the threat, the range of the impacts, and the appropriate actions to be taken.

4. Risk identification. The reports flowing into the CRG will help to identify biosecurity/bioterror risks that the disparate reports would never catch. Reports of a medical symptom or strange smell in the air may not gain much attention when reported variously in phone calls to physicians, visits to the emergency room, complaints to the power company, inquiries to city hall, and the like. However, if the same series of reports were all coming across the CRG, trained professionals would have a much better chance of quickly identifying the true nature of the event taking place and would thus be able to begin appropriate response procedures.
5. Facilitate response. Responders to a biosecurity/ bioterror event may need instructions on how to deal with a unique or especially dangerous situation. Community Response Grids would provide a means for highly specialized information to effectively reach responders.

6. Help communities with limited resources. If a biosecurity/bioterror event occurs in a small community or an area with limited resources, relevant expertise on the nature of the event could be provided to the community through the CRG.

7. Identify potentially affected social networks. If specific members of a community have been infected with a contagious pathogen, the social network components of the CRGs will be enormously helpful in identifying who else may have been exposed to the pathogen through contact with the infected people. The CRG profiles of residents can be used to identify the other members of the social networks to which the infected individuals belong. These residents can then be contacted with specific instructions through the CRG.

8. Resident-to-resident assistance. In circumstances where a biosecurity/bioterror event overwhelms the established official response capacities, the CRG could be used to disseminate guidance on how community members could safely provide resident-to-resident assistance to aid the victims in their community without endangering themselves.

9. Track external inputs into a community. Some international states have reacted poorly to potential health crises, such as viral threats like avian flu and SARS. ${ }^{54}$ Community Response Grids could be employed to gather information quickly about where member residents had traveled internationally or other types of external inputs into a community that could identify the type and origin of a biosecurity/bioterror threat introduced into a community.

10. Target the specific needs of vulnerable populations. Certain populations will need more support during different kinds of emergencies. ${ }^{55}$ Depending on the nature of the biosecurity/bioterror threat, certain populations-older adults, schoolchildren, people with certain types of disabilities or medical conditions-may need to be the focus of the attention of responders, particularly if the threat is more dangerous to people with certain medical conditions. Community Response Grids will help professional emergency responders identify who may need special attention in these circumstances based on user profiles and social networks.

There are likely other ways in which CRGs could prove very useful in response to and recovery from a biosecurity/bioterror event, but the above list provides a sense of 
the many different ways in which CRGs could contribute to preparation for and reaction to a biosecurity/bioterror event.

Community Response Grids also could be developed for specific emergency response professional communities; for example, a specialized CRG could be developed for communication and information sharing specifically among medical professionals and hospitals in a region. Recent major disasters have revealed problems in healthcare communication and coordination during emergencies, adversely affecting the delivery of healthcare. ${ }^{56,57}$ Community Response Grids designed specifically for the healthcare community in a region could address many of these concerns by facilitating information sharing, communication, and coordination of response.

\section{Future Research Directions}

As was noted earlier, the research team is currently creating and implementing a prototype CRG for the University of Maryland. This CRG provides a testbed that can be used to: (1) research the infrastructure needed to scale-up this project for use by cities and states and nationally; (2) experiment with social networking techniques to understand how to maintain readiness over long periods when there is no emergency activity; (3) develop metrics for assessing trust among residents and in the CRG infrastructure; (4) determine best practices for coordinating emergency responders and residents; (5) test the efficacy of information transfer with different user communities, both residents and professional emergency responders; (6) better integrate community response and coordination features into e-government; and (7) integrate CRGs into existing emergency response infrastructures to ensure efficient interoperability.

A range of policy issues related to CRGs_-privacy, security, accessibility, and telecommunications infrastructure issues, among others - also must be addressed as the development of CRGs is expanded, particularly to ensure access to the CRG among all members of a community. ${ }^{58}$ Given the elevated level of threats of bioterrorism and other issues of biosecurity that societies now face, the potential roles of CRGs in community response to a biosecurity/bioterror event is an extremely important dimension of future research into and development of CRGs.

The continued development of the CRG concept is fueled by the fact that information access and exchange by residents and emergency responders will be vital in the response to and recovery from any emergency. The concept of making entire communities better able to handle and recover from disasters by minimizing impacts and facilitating recovery has been labeled community resilience. ${ }^{59}$ Community Response Grids are a way of using technology to maximize community resilience.
While this new technology is still in its early stages of research, development, and implementation, there is a pressing need to begin scholarly debate and discussion about these concepts. The need to better harness the capacities of a wide range of information technologies and the social networks in a community to respond to emergencies has been reinforced by the official Virginia state report on the Virginia Tech massacre. The report makes abundantly clear that more effective information sharing, communication, and coordination could have made a tremendous difference in reducing the loss of life. ${ }^{60}$ The response to events at Virginia Tech-and to 9/11, Hurricane Katrina, and the Asian tsunami, among others-reinforces the extreme urgency of developing, testing, discussing, and improving new technologies and approaches in community emergency response.

To more effectively respond to emergencies, information and technology use by residents, responders, social networks, and entire communities in emergencies must be improved. Community Response Grids, by bridging social networks, emergency information needs, and technological capabilities, have the potential to offer hope for better access, exchange, distribution, and coordination of information in emergencies. While future emergencies cannot be prevented, research into projects like this one can help communities use technology to better respond to and recover from the emergencies that do occur.

\section{REFERENCES}

1. Cohen S, Eimicke W, Horan J. Catastrophe and public service: a case study of the government response to the destruction of the World Trade center. Public Adm Rev 2002;62:24-32.

2. Comfort LK. Shared Risk: Complex Systems in Seismic Response. New York: Pergamon; 1999.

3. Comfort LK, Kapucu N. Interorganizational coordination in extreme events: the World Trade Center attack, September 11, 2001. Natural Hazards. In press.

4. Graber AD. The Power of Communication: Managing Information in Public Organizations. Washington, DC: Congressional Quarterly; 2003.

5. Shneiderman B, Preece J. 911.gov: Community Response Grids. Science 2007;315:944.

6. Kapucu N. Interagency communication networks during emergencies: boundary spanners in multiagency coordination. Am Rev Public Admin 2004;36:207-225.

7. Kajitani Y, Okada N, Tatano H. Measuring quality of human community life by spatial-temporal age group distributions: a case study of recovery process in a disaster-affected region. Natural Hazards Rev 2005;6:41-47.

8. Shaw R, Goda K. From disaster to sustainable civil society: the Kobe experience. Disasters 2004;28(19):16-40.

9. Hagar C. The Farming Community in Crisis: The Information Needs of Cumbrian Farmers during the UK 2001 Foot and Mouth Outbreak and the Role of Information and Communica- 
tion Technologies (ICTs). Urbana-Champaign, IL: University of Illinois at Urbana-Champaign; 2005.

10. Jones C, Mitnick S. Open source disaster recovery: case studies of networked collaboration. First Monday 2006;11(5). http://www.firstmonday.org/issues/issue11_5/jones/. Accessed June 18, 2007.

11. Haddow GD, Bullock JA. Introduction to Emergency Management. Newton, PA: Buttersworth-Heinemann; 2003.

12. Chertoff M. Statement before the Senate Committee on Homeland Security and Governmental Affairs, Department of Homeland Security: Second Stage Review, July 14, 2005.

13. The White House. The Federal Response to Hurricane Katrina: Lessons Learned. Washington DC: The White House; 2006.

14. Bier V. Hurricane Katrina as bureaucratic nightmare. In: Daniels RJ, Kettl DF, Kunreuther H, eds. On Risk and Disaster: Lessons from Hurricane Katrina. Philadelphia, PA: University of Pennsylvania Press; 2006:243-254.

15. Brinkley D. The Great Deluge: Hurricane Katrina, New Orleans, and the Mississippi Gulf Coast. New York: Harper Perennial; 2006.

16. Cooper C, Block R. Disaster: Hurricane Katrina and the Failure of Homeland Security. New York: Times Books; 2006.

17. Dyson ME. Come Hell or High Water: Hurricane Katrina and the Color of Disaster. New York: Basic Books; 2005.

18. Wise CR. Organizing for homeland security after Katrina: is adaptive management what's missing? Public Adm Rev 2006;66:302-318.

19. Drabek TE. Disaster warning and evacuation responses by private business employees. Disasters 2001;25:76-94.

20. Kweit MG, Kweit RW. Citizen participation and citizen evaluation in disaster recovery. Am Rev Public Admin 2004; 34:354-373.

21. Schoch-Spana M, Franco C, Nuzzo JB, Usenza C. Community engagement: leadership tool for catastrophic health events. Biosecur Bioterror 2007;5:8-25.

22. Tierney KJ, Lindell MK, Perry RW. Facing the Unexpected: Disaster Preparedness and Response in the United States. Washington, DC: Joseph Henry Press; 2001.

23. Forrest TR. Group emergence in disasters. In: Quarantelli EL, ed. Disasters: Theory and Research. London: Sage; 1978: 105-125.

24. Wenger DE. Community response to disaster: functional and structural alterations. In: Quarantelli EL, ed. Disasters: Theory and Research. London: Sage; 1978:17-48.

25. Avdeyeva TV, Burgetova K, Welch ID. To help or not to help? Factors that determined helping responses to Katrina victims. Analyses of Social Issues and Public Policy 2006;6(1): 159-173.

26. Burkhart FN. Media, Emergency Warnings, and Citizen Response. Boulder, CO: Westview Press; 1991.

27. Lindell MK, Perry RW. Behavioral Foundations of Community Emergency Planning. Washington, DC: Taylor \& Francis; 1992.

28. Tierney K. Social inequality, hazards, and disasters. In: Daniels RJ, Kettl DF, Kunreuther H, eds. On Risk and Disaster: Lessons from Hurricane Katrina. Philadelphia, PA: University of Pennsylvania Press; 2006:109-128.

29. Covello VT. Communicating risk in crisis and noncrisis situations: tools and techniques for effective environmental communication. In Kolluru R, Bartell S, Pitblado R, Stricoff S, eds. Risk Assessment and Management Handbook for Environmental, Health, and Safety Professionals. New York: McGraw Hill; 1996:15.3-15.15.

30. Johnson BB, Slovic P. Presenting uncertainty in health risk assessment: initial studies of its effects on risk perception and trust. Risk Anal 1995;15:485-494.

31. Waugh WL. Living with Hazards, Dealing with Disasters: An Introduction to Emergency Management. New York: M E Sharpe; 2000.

32. Kettl DF. System under Stress: Homeland Security and American Politics. Washington: Congressional Quarterly; 2004.

33. Pelfrey WV. The cycle of preparedness: establishing a framework to prepare for terrorist threats. Journal of Homeland Security and Emergency Management 2005;2(1):1-21.

34. Waugh WL, Sylves RT. Organizing the war on terrorism. Public Adm Rev 2002;62:145-153.

35. Cox J. Communicating even when the network's down. Network World 2006. www.networkworld.com/news/2006/ 111606-dtn.html. Accessed November 12, 2007.

36. Ikeda Y, Beroggi GEG, Wallace WA. Evaluation of multi-group emergency management with multimedia. International Journal of Risk Assessment and Management 2001;2:263-275.

37. Mendonca D, Wallace WA. Development of a decision logic to support group improvisation: an application to emergency response. In: Proceedings of the 35th Annual Hawaii International Conference on System Sciences (HICSS), Hawaii, USA; 2002:2882-2888.

38. Klinenberg E. Fighting for Air: The Battle to Control America's Media. New York: Metropolitan Books; 2007.

39. Vaidhyanathan S. Me, 'Person of the Year'? no thanks. MSNBC December 28, 2006. http://www.msnbc.msn.com/ id/16371425/. Accessed November 12, 2007.

40. Will BH. The public library as community crisis center. Libr J 2001;126(20):75-77.

41. Dearstyne BW. The FDNY on 9/11: information and decision making in crisis. Gov InfQ2007;24:29-46.

42. Dearstyne BW. Taking charge: disaster fallout reinforces RIM's importance. Information Management Journal 2006; July/August:37-42.

43. Matthews G. Disaster management: sharing experience, working across the sector. Journal of Librarianship and Information Science 2005;37(2):63-74.

44. Dearstyne BW. Fighting terrorism, making war: critical insights in the management of information and intelligence. Gov Inf Q2005;22:170-186.

45. Chadwick A. Internet Politics: States, Citizens, and New Communication Technologies. New York: Oxford University Press; 2006.

46. Silver D. The soil of cyberspace: historical archaeologies of the Blacksburg Electronic Village and the Seattle Community Network. In: Schuler D, Day P, eds. Shaping the Network Society: The New Role of Civil Society in Cyberspace. Cambridge, MA: MIT Press; 2004:301-324.

47. van den Besselaar P, Koizumi S, eds. Digital Cities III. Information Technologies for Social Capital: Cross-cultural Perspectives. Berlin: Springer; 2005.

48. Fleischmann KR. Digital libraries with embedded values: combining insights from LIS and science and technology studies. Library Quarterly. In press.

49. Jaeger PT, Fleischmann K. Public libraries, values, trust, and e-government. Information Technology and Libraries 2007; 26(4):35-43. 
JAEGER ET AL.

50. Bertot JC, Jaeger PT, Langa LA, McClure CR. Public access computing and Internet access in public libraries: the role of public libraries in e-government and emergency situations. First Monday 2006;11(9). http://www.firstmonday.org/issues/issue11_9/bertot/. Accessed June 18, 2007.

51. Bertot JC, Jaeger PT, Langa LA, McClure CR. Drafted: I want you to deliver e-government. Libr J 2006;131(13): 34-39.

52. Jaeger PT, Langa LA, McClure CR, Bertot JC. The 2004 and 2005 Gulf Coast hurricanes: evolving roles and lessons learned for public libraries in disaster preparedness and community services. Public Library Quarterly 2007;25(3/4): 199-214.

53. McNutt JG. Electronic government, the Internet, and disasters. DttP: Documents to the People 2006;34(1):17-21.

54. Patrick $S$. Weak states and global threats: fact or fiction. Wash Q 2006;29(2):27-53.

55. Wu PF, Preece J, Shneiderman B, Jaeger PT, Qu Y. Community response grids for older adults: motivations, usability, and sociability. Paper presented at the 13th Americas Conference on Information Systems; Keystone, CO; August 2007.

56. Franco C, Toner E, Waldhorn R, Maldin B, O’Toole T, Inglesby T. Systematic collapse: medical care in the aftermath of hurricane Katrina. Biosecur Bioterror 2004;4:135-146.
57. Maldin B, Lam C, Franco C, et al. Regional approaches to hospital preparedness. Biosecur Bioterror 2007;5:43-53.

58. Jaeger PT, Shneiderman B, Fleischmann KR, Preece J, Qu Y, Wu FP. Community response grids: e-government, social networks, and effective emergency response. Telecommunications Policy 2007;31:592-604.

59. Ronan KR, Johnson DM. Promoting Community Resilience in Disasters: The Role for Schools, Youth, and Families. New York: Springer; 2005.

60. Virginia Tech Review Panel. Mass Shooting at Virginia Tech: Report of the Review Panel. Richmond, VA: Commonwealth of Virginia; 2007. http://www.governor.virginia.gov/ TempContent/techPanelReport-docs/FullReport.pdf. Accessed November 12, 2007.

Manuscript received June 23, 2007;

accepted for publication October 18, 2007.

Address reprint requests to:
Paul T. Jaeger, PhD
College of Information Studies
University of Maryland
4105 Hornbake Building
College Park, MD 20742-4345
E-mail: pjaeger@umd.edu 
